\title{
Towards a Better Understanding of the Mechanical Behavior of a Fixed Bed of Eucalyptus Charcoal in a Blast Furnace Using a Specific Compression test
}

\author{
Maíra Reis de Assis, ${ }^{\mathrm{a}}$ Loïc Brancheriau, ${ }^{\mathrm{b}, *}$ Daniel Guibal, ${ }^{\mathrm{b}}$ Alfredo Napoli, ${ }^{\mathrm{b}}$ and \\ Paulo Fernando Trugilho ${ }^{\mathrm{b}}$
}

\begin{abstract}
The properties of wood charcoal layers have an effect on the performance of small-scale blast furnaces. In order to characterize the mechanical behavior of a fixed bed of eucalyptus charcoal, a specific uniaxial compression test was designed and used with charcoal layers of different characteristics. This layer test has the potential to be standardized, and it made it possible to consider the bulk properties of randomly layout charcoal pieces, which was better adapted than single specimen tests in the fiber direction. A total of eight charcoal layers were prepared with two carbonization temperatures $\left(500^{\circ} \mathrm{C}\right.$ and $\left.900{ }^{\circ} \mathrm{C}\right)$, two granularities $(10 \mathrm{~mm}$ and $20 \mathrm{~mm}$ ), and two different testing temperatures $\left(20^{\circ} \mathrm{C}\right.$ and $\left.300^{\circ} \mathrm{C}\right)$. Characteristic parameters of the compression tests were then determined as the particle size distribution, the mechanical energy, and the mean power. The charcoal produced at $900^{\circ} \mathrm{C}$ and with a granularity of $20 \mathrm{~mm}$ was more resistant to breakage than the others were, and a high quantity of large particles remained after the tests. Significant correlations existed between the carbonization temperature, granularity, and mechanical power of the compression test. The mechanical power was the main parameter that determined the resistance to breakage of a charcoal bed in compression.
\end{abstract}

Keywords: Bulk compression; Mechanical strength; Carbonization temperature

Contact information: a: Universidade Federal de Lavras, Department of Forest Sciences, Lavras, Minas Gerais, Brazil; b: Research Unit BioWooEB, CIRAD, Université Montpellier, 34398 Montpellier, France;

*Corresponding author: loic.brancheriau@cirad.fr

\section{INTRODUCTION}

Wood charcoal, a renewable and less polluting energy source than coke coal, can be used in small-scale blast furnaces. Charcoal is the most expensive raw material that comprises the load in blast furnaces (Norgate and Langberg 2009). The increasing interest of metallurgists in the use of wood charcoal for ironmaking has led to a need to better understand its properties (chemical, physical, and mechanical). Wood charcoal's physical properties influence the performance of the blast furnace, and its chemical composition is related to the amount of charcoal needed to produce a ton of iron, as well as the composition of the pig iron and steel produced (Gupta 2003; Babich et al. 2010). Although it has some advantages over coke in terms of higher reactivity and lower ash contents, charcoal is mechanically unstable compared to coke (Antal and Grønli 2003; De Assis et al. 2016). It has inherently lower mechanical strength and higher friability, imposing difficulties related to its transport, handling, and use in processes.

There is no standardized method for evaluating the mechanical strength of charcoal. The experimental results obtained by steel companies do not provide a basis for proposing 
a unique methodology (Raad and Melo 2014). Furthermore, the methods previously published consisted of using single specimens and compressing them in the direction of the fibers (Doat and Petroff 1975; Oliveira et al. 1982; Kumar et al. 1999; Vieira 2009). As charcoal is irregularly shaped, granular, and anisotropic, compression tests in the axial direction using prepared specimens may not reveal the mechanical behavior of a charcoal bed. The load on charcoal is not exclusively applied along the fiber direction in industrial conditions, but randomly applied on the particles.

The objective of this study was to propose an approach to quantify the effects of applying load on randomly distributed bulk charcoal. The authors hypothesized that application of a single specific compression test can make it possible to determine the mechanical behavior, the strength, and the friability of a charcoal bed. The methodology tried to produce conditions similar to those encountered in a blast furnace. It was possible to describe the behavior of charcoal through the index of particle size distribution, the energy, and the mean power associated with the compression test. The innovation was both constituted by the design of the specific compression test and by the analysis of the characteristic parameters link for a charcoal bed.

\section{EXPERIMENTAL}

\section{Materials}

A total of 73 trees of one hybrid clone of Eucalyptus urophylla ST Blake (6 years old) were harvested. The trees came from a commercial plantation belonging to GERDAU S.A., and were located in the same plot at Santo Antônio do Amparo, Minas Gerais, Brazil $\left(20^{\circ} 56^{\prime} 48^{\prime}\right.$ ' $\mathrm{S}$ and $44^{\circ} 55^{\prime} 09^{\prime}$ ' $\mathrm{O}$, altitude $\left.1000 \mathrm{~m}\right)$. The plantation density was 1190 trees/ha $(3.0 \times 2.8 \mathrm{~m}$ spacing $)$. One log per tree, of $1 \mathrm{~m}$ length, was cut at $0.3 \mathrm{~m}$ from the base of the tree. In the central boards, 118 wood samples were made considering three radial positions from pith to bark: internal, middle, and external. The dimensions of the wood samples were $30 \times 30 \times 200 \mathrm{~mm}^{3}$ (in radial, tangential, and longitudinal directions, respectively). The samples were sorted according to their wood density. The even ranks were associated with a carbonization temperature of $500{ }^{\circ} \mathrm{C}$, and the odd ranks with a temperature of $900{ }^{\circ} \mathrm{C}$. Carbonization was performed in a specific electric reactor developed for this study (Macro-ATG; Cirad, Montpellier, France), using a heating rate of $1{ }^{\circ} \mathrm{C} / \mathrm{min}$. The carbonizations were conducted under an inert atmosphere (nitrogen) with a gas flow of $10 \mathrm{Nl} \cdot \mathrm{min}^{-1}$, an initial temperature of $40{ }^{\circ} \mathrm{C}$, and a residence time of one hour (for a final temperature of $500{ }^{\circ} \mathrm{C}$ ) and two hours (for a final temperature of $900{ }^{\circ} \mathrm{C}$ ). Two granularities were selected of 10 and $20 \mathrm{~mm}$ for the study as packing density is a key feature of a granular medium (Zhang 2018). The particle sizing before (granularity of 10 and 20 $\mathrm{mm}$ ) and after the compressions tests (sieving of 8,4 , and $1.6 \mathrm{~mm}$ ) were carried out with a vibrating shaker equipped with a sieve stack (EFL2000/1; Endecotts, London, England).

\section{Methods}

Compression test designed for charcoal beds

A universal testing machine was used (model DY36; Adamel Lhomargy, Ivry-surSeine, France) with a force applied at a constant speed of $0.02 \mathrm{~mm} / \mathrm{s}$ up to a maximum of $12 \mathrm{kN}$. A cell containing the charcoal bed was added to the testing machine (Fig. 1). This cell was a hollow cylinder of $150 \mathrm{~mm}$ in internal diameter (which provided a controlled temperature), closed by two elements acting as a piston. The thickness of the charcoal bed 
in the cylinder was $15 \mathrm{~cm}$. Compression tests were performed at two temperatures, $20^{\circ} \mathrm{C}$ and $300{ }^{\circ} \mathrm{C}$. The temperature of $300{ }^{\circ} \mathrm{C}$ was set due the flammability limit point of charcoal in the presence of oxygen. A total of six treatments were tested: two carbonization temperatures $\left(500{ }^{\circ} \mathrm{C}, 900{ }^{\circ} \mathrm{C}\right)$, two granularities $(10 \mathrm{~mm}, 20 \mathrm{~mm})$, and two temperatures of compression test $\left(20^{\circ} \mathrm{C}, 300^{\circ} \mathrm{C}\right)$.

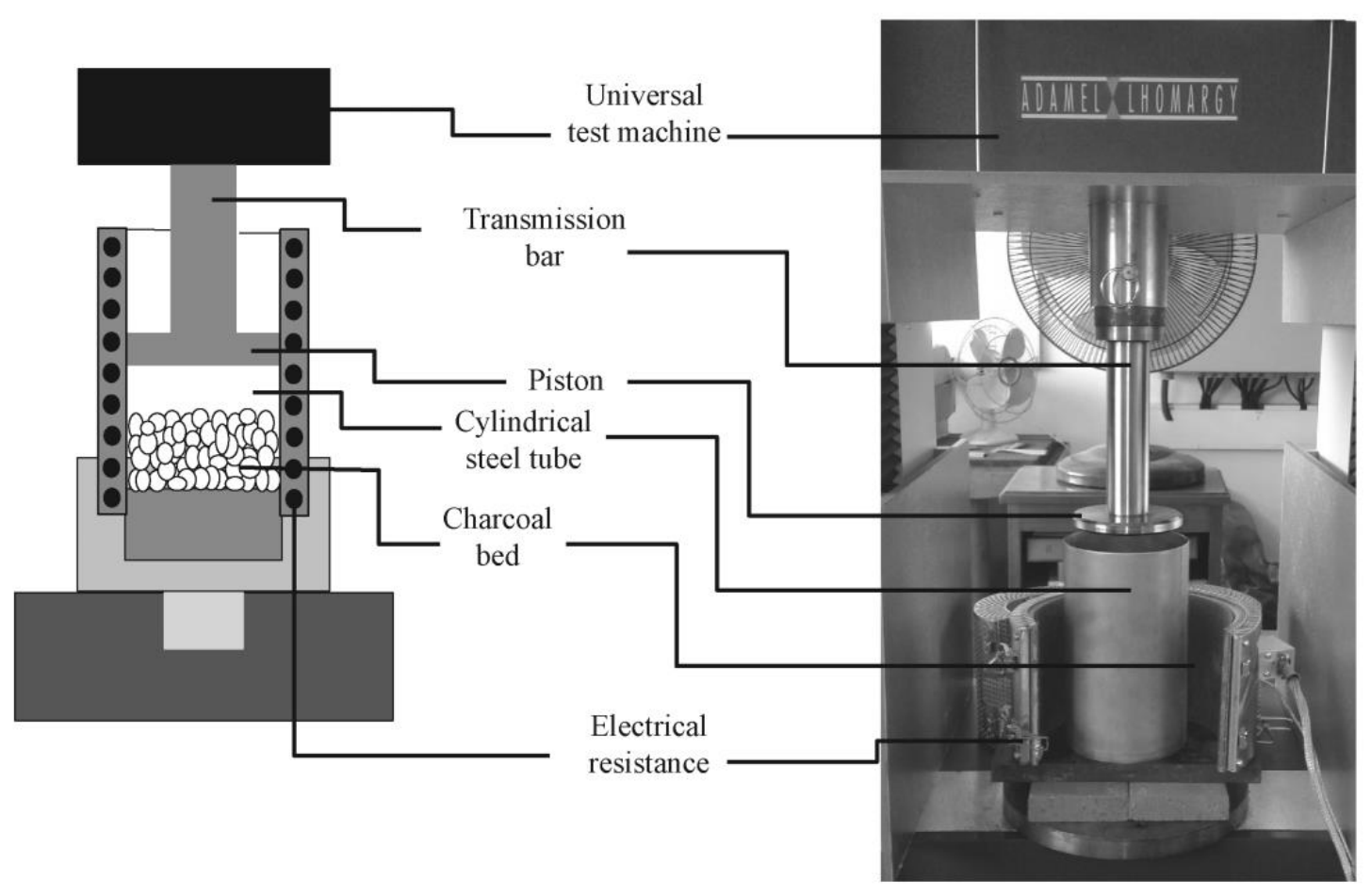

Fig. 1. Experimental device for compression tests

\section{Determination of characteristic parameters}

The charcoal bed was weighed before testing. After the compression tests, the charcoal was recovered, weighed, and sorted by category of particle size. The charcoal was weighed to control the loss of material before and after the tests. The categories were obtained by sieving with openings of 8,4 , and $1.6 \mathrm{~mm}$. Particles lower than $1.6 \mathrm{~mm}$ were considered as a fine fraction. The index of particle size distribution was defined by Eq. 1 ,

$$
P S D=\left(W_{C} / W_{T}\right) \times 100
$$

where $P S D$ is the index of particle size distribution (\%), $W c$ is the weight of the particle size category $(\mathrm{kg})$, and $W_{T}$ is the total weight $(\mathrm{kg})$.

The force-displacement data were recorded during each compression test (Fig. 2). The energy and power were defined by Eq. 2 and Eq. 3, respectively,

$$
\begin{aligned}
& E=\int_{0}^{D} F d x \\
& P=E /(\Delta t)
\end{aligned}
$$

where $E$ is energy $(\mathrm{J}), F$ is the applied load $(\mathrm{N}), D$ is the total displacement $(\mathrm{m}), P$ is power $(\mathrm{W})$, and $\Delta t$ is the total elapsed time (s) of the test (between $10 \mathrm{~N}$ and $12000 \mathrm{~N}$ ). 


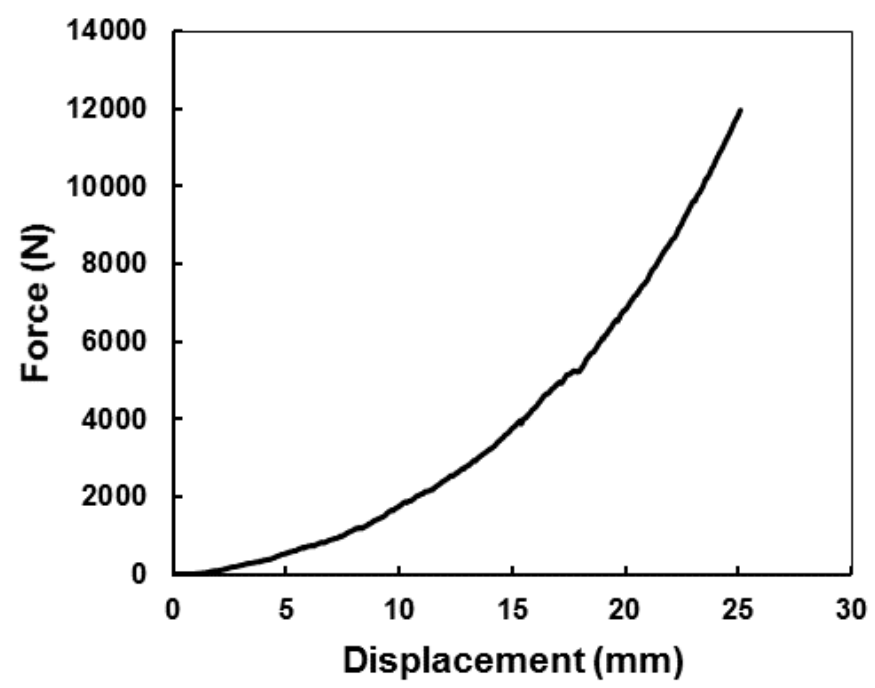

Fig. 2. The load-displacement curve associated with a compression test of charcoal bed (temperature of carbonization $900^{\circ} \mathrm{C}$, particle size of $10 \mathrm{~mm}$, test temperature of $20^{\circ} \mathrm{C}$ )

\section{Data Analysis}

The analysis was carried out using XLSTAT software (Addinsoft, 2019.1.3). The distributions of particle size indexes were first computed taking into account the experimental factors of carbonization temperature and initial granularities. The bilateral Pearson's correlation coefficients between the characteristic parameters were then determined with the associated significance test. In the last step, a principal component analysis was performed on the characteristic parameters, followed by a hierarchical clustering analysis using the principal components.

\section{RESULTS AND DISCUSSION}

The indexes of particle size distribution obtained by compression tests at $20^{\circ} \mathrm{C}$ and $300^{\circ} \mathrm{C}$ are presented in Figs. 3 and 4, respectively. The particle size distribution was linked with the carbonization temperature. Charcoal produced at $900{ }^{\circ} \mathrm{C}$ maintained a high proportion of particles $>8 \mathrm{~mm}$, independent of compression temperature and granularity. Charcoal at $500{ }^{\circ} \mathrm{C}$ generally showed a higher level of brittleness with fewer particles in the $>8 \mathrm{~mm}$ category independent of test conditions. In addition, samples exposed to the highest compression temperature showed fewer particles in the $>8 \mathrm{~mm}$ category. The charcoal beds with a granularity of $20 \mathrm{~mm}$ had a higher resistance (less deformation due to the applied load) than those of $10 \mathrm{~mm}$. There were a larger number of particles close to the original size (> $8 \mathrm{~mm}$ category).

The influence of the carbonization temperature on the compressive strength in charcoal was previously reported (Oliveira et al. 1982). The present study observed an increase in compression strength with an increase in temperature from 300 to $900{ }^{\circ} \mathrm{C}$ for eucalyptus. At $900{ }^{\circ} \mathrm{C}$, the resistance to compression was higher than at $500{ }^{\circ} \mathrm{C}$. This increase in strength was related to the increase in the amount of fiber per unit of area (linked to porosity). The carbonization temperature had a remarkable influence on pore volume in charcoal (Baileys and Blankenhorn 1982). 
(a)

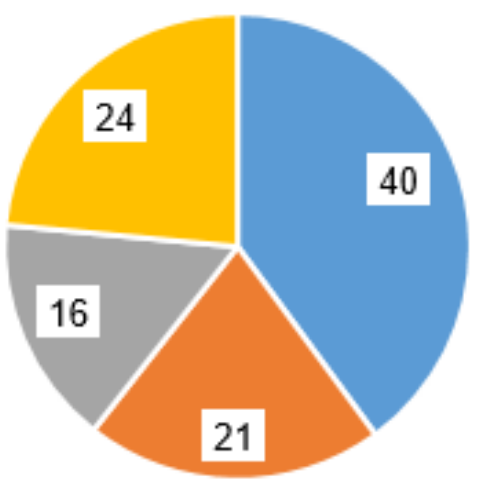

(c)

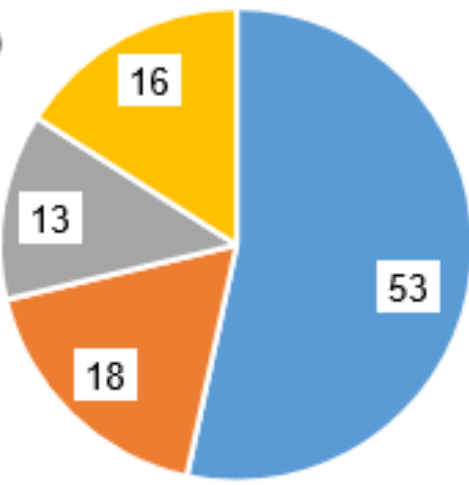

(b)

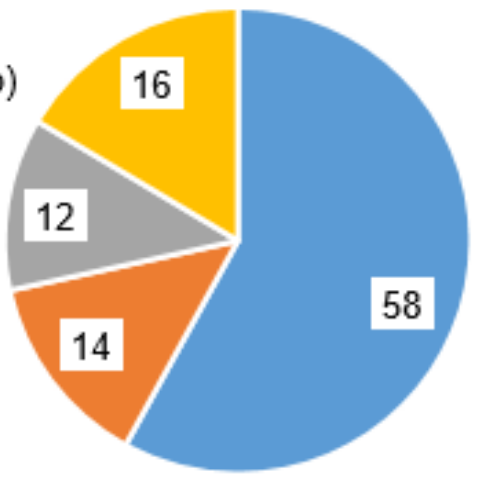

(d)

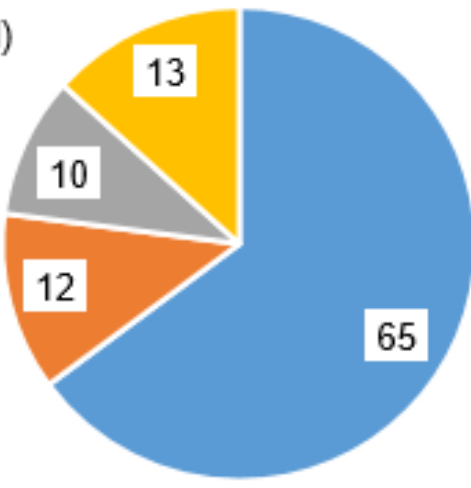

$$
\text { " }>8 \mathrm{~mm}=8-4 \mathrm{~mm}=4-1.6 \mathrm{~mm}=<1.6 \mathrm{~mm}
$$

Fig. 3. Particle size distribution (\%) after a compression test temperature of $20^{\circ} \mathrm{C}$. (a) Temperature of carbonization $500^{\circ} \mathrm{C}$ and granularity $10 \mathrm{~mm}$; (b) $500^{\circ} \mathrm{C}, 20 \mathrm{~mm}$; (c) $900^{\circ} \mathrm{C}, 10 \mathrm{~mm}$; (d) $900^{\circ} \mathrm{C}$, $20 \mathrm{~mm}$

Charring temperature greatly affects the structure of charcoal. The increase in compression strength was related to a structural rearrangement of charcoal components, especially carbon (detailed in the review of De Assis et al. 2016). The higher the temperature the more resistant the charcoal structure. The carbonized wood presents graphite-type crystallites. The increase in the final temperature of carbonization (from 400 to $600{ }^{\circ} \mathrm{C}$, in most cases) results in an increase in the proportion of aromatics $\mathrm{C}$ and/or the size of the aromatic $\mathrm{C}$ agglomerate. A change from "amorphous" (disordered) to "crystalline" (ordered) structure is thus induced by the temperature, increasing the mechanical strength of charcoal.

The present study also reported an increase in porosity with the increase in temperature until $500{ }^{\circ} \mathrm{C}$. The effect of porosity on compression strength was also observed by De Andrade and Lucia (1995) until $500{ }^{\circ} \mathrm{C}$. In blast furnaces, the permeability (passage of gases through the load) is strongly affected by the particle size distribution. The low mechanical strength of charcoal affects the load size distribution in the furnace due to the greater generation of fine fractions on handling and under load weight. This prevents the contact of the gas with the metal charge due to the formation of preferential paths within the blast furnace, changing ore reduction reactions. Charcoal mechanical strength determines the effective height, the internal volume, and consequently, the capacity and performance of the blast furnace (Raad and Melo 2014). 


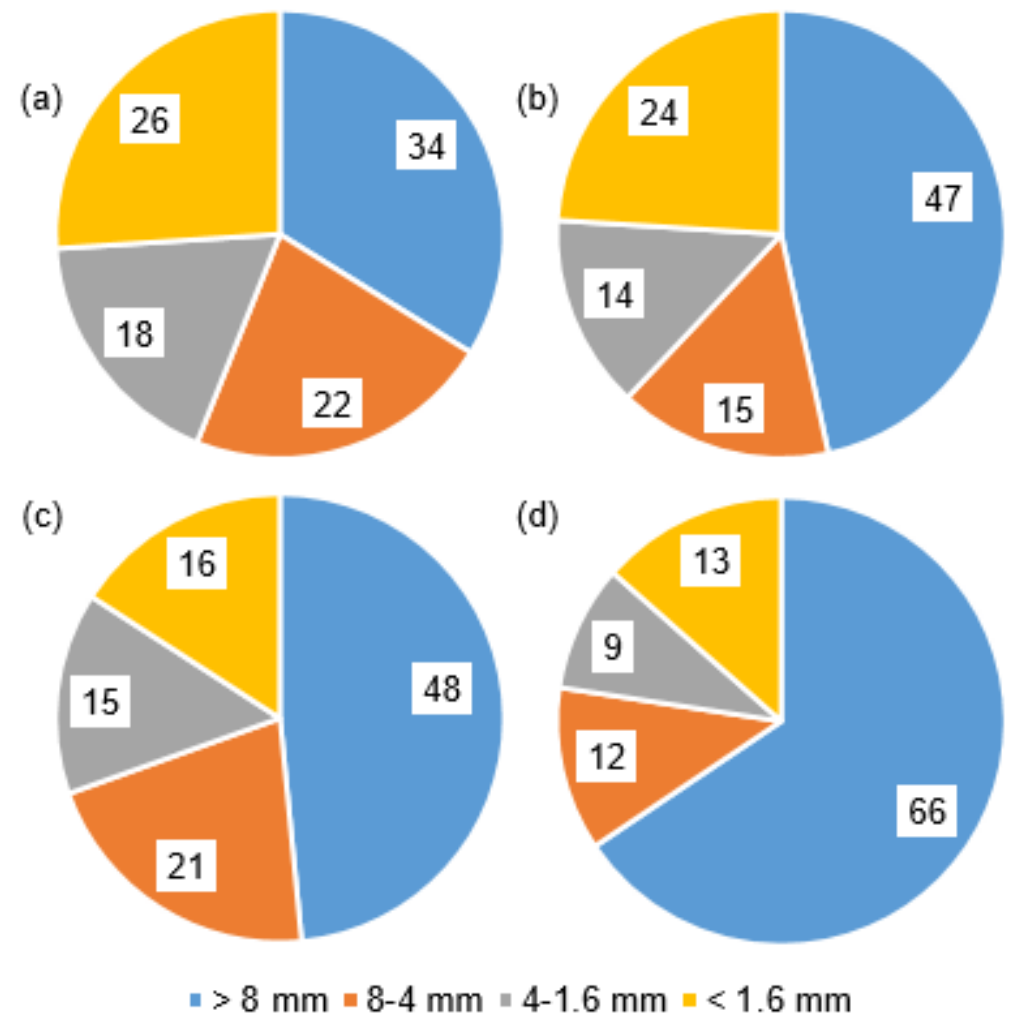

Fig. 4. Particle size distribution (\%) after a compression test temperature of $300{ }^{\circ} \mathrm{C}$.

(a) Temperature of carbonization $500^{\circ} \mathrm{C}$ and granularity $10 \mathrm{~mm}$; (b) $500^{\circ} \mathrm{C}, 20 \mathrm{~mm}$; (c) $900{ }^{\circ} \mathrm{C}$, $10 \mathrm{~mm}$; (d) $900^{\circ} \mathrm{C}, 20 \mathrm{~mm}$

Table 1. Power and Energy Values According to the Temperature of Carbonization, the Granularity, and the Temperature of the Compression Test

\begin{tabular}{|c|c|c|c|c|}
\hline $\begin{array}{c}\text { Temperature of } \\
\text { Carbonization }\left({ }^{\circ} \mathbf{C}\right)\end{array}$ & $\begin{array}{c}\text { Granularity } \\
(\mathbf{m m})\end{array}$ & $\begin{array}{c}\text { Temperature of } \\
\text { Test }\left({ }^{\circ} \mathbf{C}\right)\end{array}$ & $\begin{array}{c}\text { Power } \\
\left(\mathbf{1 0}^{-3} \cdot \mathbf{W}\right)\end{array}$ & Energy (J) \\
\hline 500 & 10 & 300 & 15.6 & 86.2 \\
\hline 500 & 10 & 20 & 17.5 & 108.3 \\
\hline 500 & 20 & 300 & 17.0 & 112.3 \\
\hline 500 & 20 & 20 & 17.9 & 125.5 \\
\hline 900 & 10 & 300 & 17.9 & 71.1 \\
\hline 900 & 10 & 20 & 19.2 & 98.5 \\
\hline 900 & 20 & 20 & 20.4 & 108.6 \\
\hline 900 & 20 & 300 & 20.5 & 74.8 \\
\hline
\end{tabular}

Table 1 shows the values of power and energy according the experimental conditions. The power values were ranked with the carbonization temperature and the granularity. The power increased with the carbonization temperature and the granularity. The energy and the test temperature appeared to be not linked with the other measured characteristics. The bilateral correlation coefficients between power, energy, and indexes of particle size distribution are displayed in Table 2. There were significant negative correlations between the $>8 \mathrm{~mm}$ category and the other lower sizes. The power parameter was also strongly linked with the $>8 \mathrm{~mm}$ category. A high value of power was associated 
with a high index of particle size distribution (high percentage of large particles). As observed in Table 1, the energy parameter was not linked with the other characteristics in Table 2.

Table 2. Bilateral Pearson's Correlation between Measured Properties

\begin{tabular}{|c|c|c|c|c|c|}
\hline Property & Power & Energy & $>\mathbf{8} \mathbf{~ m m}$ & $\mathbf{8}$ to $\mathbf{4} \mathbf{~ m m}$ & $\mathbf{4}$ to $1.6 \mathbf{~ m m}$ \\
\hline Energy & -0.10 & & & & \\
\hline$>\mathbf{8} \mathbf{~ m m}$ & $0.91^{*}$ & 0.06 & & & \\
\hline $\mathbf{8}$ to $\mathbf{4} \mathbf{~ m m}$ & $-0.72^{*}$ & -0.32 & $-0.90^{*}$ & & \\
\hline $\mathbf{4}$ to $\mathbf{1 . 6} \mathbf{~ m m}$ & $-0.92^{*}$ & -0.08 & $-0.99^{*}$ & $0.92^{*}$ & \\
\hline$<\mathbf{1 . 6} \mathbf{~ m m}$ & $-0.89^{*}$ & 0.17 & $-0.91^{*}$ & 0.63 & $0.86^{*}$ \\
\hline * Significance level at $5 \%$
\end{tabular}

A hierarchical clustering analysis (HCA) was performed on the components obtained by a principal component analysis (PCA). Two components were identified by PCA, which represented $94 \%$ of the original variance of the power, energy, and indexes of particle size distribution values. The Ward method with the Euclidian distance was used to perform the HCA. The dendrogram obtained by HCA (Fig. 5) showed two separate groups. The four first test conditions on the left of the figure are those associated with a high power value and large particles (high mechanical strength). The charcoal produced at different temperatures stood out. The granularity also influenced the clustering but had less effect than the carbonization temperature. The test temperature of $300{ }^{\circ} \mathrm{C}$ was observed to be more present in the group of less mechanical strength. However, temperature is not a cumulative effect (De Assis et al. 2016). The time of reduction in charcoal between the initial carbonization temperatures of $500{ }^{\circ} \mathrm{C}$ and $900{ }^{\circ} \mathrm{C}$ tended to be close, and the mechanical behavior of both carbonization temperatures tended to be similar.

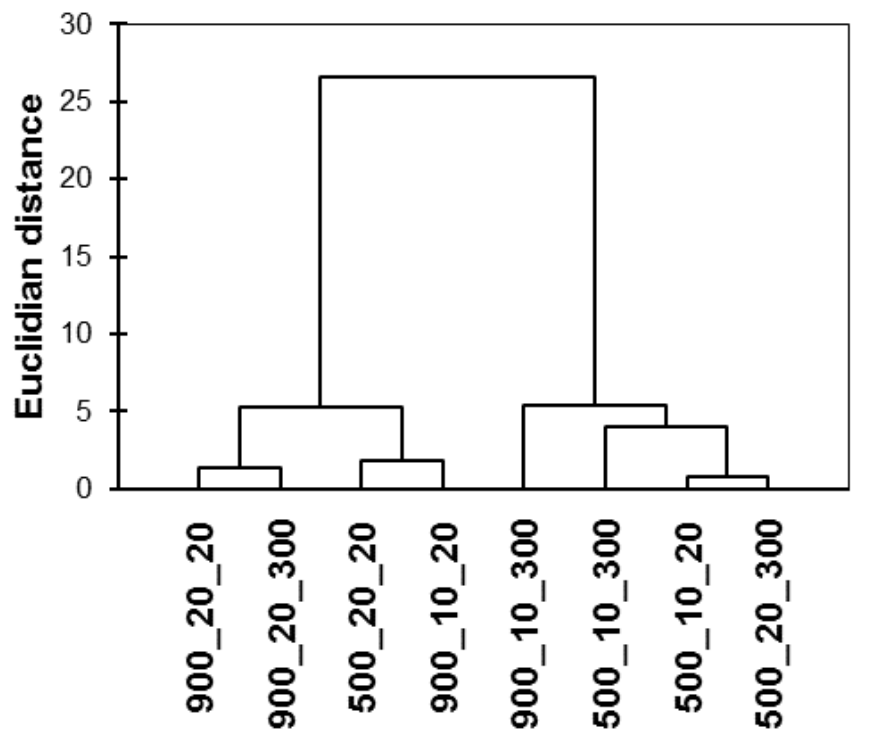

Fig. 5. Hierarchical clustering dendrogram of the compression test conditions computed on the values of the characteristics; test conditions noted as carbonization temperature _ granularity test temperature 
A charcoal layer is a granular material defined as an aggregate of discrete macroscopic particles. The mechanical behavior of granular material is mainly a function of the size, shape, strength of particles, and the relative arrangement of voids and particles (Liu et al. 1999; Yu 2004; Zhang 2018). The particle strength explained the macroscopic deformation of crushable aggregates related to compression tests (McDowell and Bolton 1998). It could also directly affect the particle size distribution (McDowell et al. 1996), the contact between particles (Miura et al. 1984), and the solid fraction (porosity) (Cheng et al. 2008). The particle size and shape were reported to be the most important variables in the packing density (Finney 1970; Donev et al. 2004; Baker and Kudrolli 2010). The packing density was found to reach a maximum value when the particles are cube-shaped, and decreased as the number of sides increased (Li et al. 2010).

Authors studied the relationship between the shatter index (impact strength), the shape of the particles used, and the carbonization temperature (Kumar et al. 1999). It was observed that smaller and granular forms had a lower impact strength than larger samples prepared in cubic forms. The authors attributed this fact to the difference in their crosssectional area and the distribution of load on their surfaces. In comparison to cubic samples, lumps had smaller cross-sectional areas and irregular shape, and hence the load applied was concentrated into certain small regions. Thus, the result was more breakage in lumpy samples. In the case of cubes, the load applied was distributed over the large cross-sectional area, and hence, less breakage occurred.

The contact points between particles transferred the normal forces, the shear forces, and the bending moments in the aggregate. An important characteristic of the granular material was that there was a loss of energy between two particles when they interacted with each other. Interactions between particles induced a non-linear behavior, as there was friction between particles at their contact points (Franklin and Shattuck 2016). Thus, the authors assumed that the increase of friction when the load was applied in a compression explained the absence of correlation between the power and energy measured. The global behavior of a charcoal bed under a compression load was an iterative process that led to the decrease of porosity (no more void at the end of this process). When the load was applied, concentration stresses appeared at the contact points until the breakage of the particles. The stress levels decreased after the breakage. A rearrangement of the aggregate then occurred with a loss of energy by friction and an increase in the packing density. New contact points between particles were formed and the concentration stresses increased again, which led to a new iteration of this process.

\section{CONCLUSIONS}

1. As no standardized method exists for evaluating the mechanical strength of charcoal, an innovative approach to quantify the effects of applying load on randomly distributed bulk charcoal was proposed, which both allowed quantifying mechanical and friability parameters. The methodology tried to produce conditions similar to those encountered in a blast furnace.

2. The bulk behavior of charcoal beds was influenced by carbonization temperature and granularity. Charcoal produced at $900{ }^{\circ} \mathrm{C}$ and prepared with a granularity of $20 \mathrm{~mm}$ gave a high proportion of fragments $>8 \mathrm{~mm}$ after the compression test. The 
carbonization temperature was the main factor influencing the mechanical resistance, followed by the granularity.

3. The test temperature did not have a major effect, but the tests performed at $300{ }^{\circ} \mathrm{C}$ were more present in the group of low mechanical resistance to breakage. Further investigations remain to be done at higher test temperatures to better understand the coupling between temperatures of carbonization and test.

4. The mechanical power was positively correlated with the carbonization temperature and the granularity. A high mechanical power was characteristic of a resistant charcoal layer.

5. Considering charcoal aggregates as granular materials, the mechanics of charcoal behavior were a function of the particles' strength, shape, size, and packing density. As the load increased during the test, the number of contacts between particles also increased, producing energy losses by friction. This non-linear behavior could explain why the mechanical energy was not correlated with the other computed parameters. Further investigations might use the experimental load-displacement curves with a specific granular modeling, or by considering the modeling of the behavior of a charcoal layer as a viscous flow of a continuous medium.

\section{ACKNOWLEDGMENTS}

This study was supported by UFLA (Lavras, Brazil), CIRAD (Montpellier, France), and IRD (Montpellier, France) and was conducted between 2013 and 2016. The authors are grateful to these institutes for their scientific, technical, and financial support.

\section{REFERENCES CITED}

Antal, M. J., and Grønli, M. (2003). "The art, science and technology of charcoal production," Industrial \& Engineering Chemistry Research 42(8), 1619-1640. DOI: 10.1021/ie0207919

Babich, A., Senk, D., and Fernandez, M. (2010). "Charcoal behavior by its injection into the modern blast furnace," ISIJ International 50(1), 81-88. DOI:

10.2355/isijinternational.50.81

Baileys, R. T., and Blankenhorn, P. R. (1982). "Calorific and porosity development in carbonized wood," Wood Science 15(1), 19-28.

Baker, J., and Kudrolli, A. (2010). "Maximum and minimum stable random packings of platonic solids," Physical Review E 82(6), Article ID 061304. DOI: 10.1103/PhysRevE.82.061304

Cheng, H., Nakata, Y., and Bolton, M. D. (2008). "Micro- and macro-mechanical behavior of DEM crushable materials," Géotechnique 58(6), 471-480. DOI: 10.1680/geot.2008.58.6.471

De Andrade, A. M., and Lucia, R. M. D. (1995). "Evaluation of the charcoal hygroscopicity and its effects on resistance to crushing," Floresta e Ambiente 1995(2), 19-26. (In Portuguese) 
De Assis, M. R., Brancheriau, L., Napoli, A., and Trugilho, P. F. (2016). "Factors affecting the mechanics of carbonized wood: Literature review," Wood Science and Technology 50(3), 519-536. DOI: 10.1007/s00226-016-0812-6

Doat, J., and Petroff, G. (1975). "La carbonisation des bois tropicaux. Essais de laboratoire et perspectives industrielles [The carbonization of tropical woods: Laboratory tests and industrial prospects]," Revue Bois et Forêts des Tropiques 159, 55-71.

Donev, A., Cisse, I., Sachs, D., Variano, E. A., Stillinger, F. H., Connelly, R., Torquato, S., and Chaikin, P. M. (2004). "Improving the density of jammed disordered packings using ellipsoids," Science 303(5660), 990-993. DOI: 10.1126/science.1093010

Finney, J. L. (1970). "Random packings and the structure of simple liquids. I. The geometry of random close packing," Proceedings of the Royal Society of London A: Mathematical, Physical and Engineering Sciences 319(1539), 479-493. DOI: 10.1098/rspa.1970.0189

Franklin, S. V., and Shattuck, M. D. (2016). Handbook of Granular Materials, First Edition, CRC Press, Boca Raton, FL, USA.

Gupta, R. C. (2003). "Woodchar as a sustainable reductant for ironmaking in the $21^{\text {st }}$ century," Mineral Processing and Extractive Metallurgy Review 24(3-4), 203-231. DOI: $10.1080 / 714856822$

Kumar, M., Verma, B. B., and Gupta, R. C. (1999). "Mechanical properties of Acacia and Eucalyptus wood chars," Energy Sources 21(8), 675-685. DOI: 10.1080/00908319950014425

Li, S. X., Zhao, J., Lu, P., and Xie, Y. (2010). "Maximum packing densities of basic 3D objects," Chinese Science Bulletin 55(2), 114-119. DOI: 10.1007/s11434-009-0650-0

Liu, L. F., Zhang, Z. P., and Yu, A. B. (1999). "Dynamic simulation of the centripetal packing of mono-sized spheres," Physica A: Statistical Mechanics and its Applications 268(3), 433-453. DOI: 10.1016/S0378-4371(99)00106-5

McDowell, G. R., Bolton, M. D., and Robertson, D. (1996). "The fractal crushing of granular materials," Journal of the Mechanics and Physics of Solids 44(12), 20792101. DOI: 10.1016/S0022-5096(96)00058-0

McDowell, G. R., and Bolton, M. D. (1998). "On the micromechanics of crushable aggregates," Géotechnique 48(5), 667-679. DOI: 10.1680/geot.1998.48.5.667

Miura, N., Murata, H., and Yasufuku, N. (1984). "Stress-strain characteristics of sand in a particle-crushing region," Soils and Foundations 24(1), 77-89. DOI: 10.3208/sandf1972.24.77

Norgate, T., and Langberg, D. (2009). "Environmental and economic aspects of charcoal use in steelmaking," ISIJ international 49(4), 587-595. DOI: 10.2355/isijinternational.49.587

Oliveira, J. B., Gomes, P. A., and Almeida, M. R. (1982). Preliminary Studies on Standardization of Tests for the Charcoal Quality Control (Technical Report STP006), Fundação Centro Tecnológico de Minas Gerais, Belo Horizonte, Brazil. (In Portuguese)

Raad, T. J., and Melo, V. F. (2014). Mapping of Institutional Actions for the Sustainability of Pig Iron Production from Charcoal (Technical Report CGEE/MDIC 49/2013), Centro de Gestão e Estudos Estratégicos, Brasília, Brazil. (In Portuguese)

Vieira, R. S. (2009). Mechanical Properties of Wood of Eucalyptus Clones and Charcoal Produced Between $350^{\circ} \mathrm{C}$ and $900{ }^{\circ} \mathrm{C}$, Ph.D. Dissertation, Universidade Federal de Lavras, Lavras, Brazil. 
Yu, A. (2004). "Discrete element method-An effective method for particle scale research of particulate matter," Engineering Computations 21(2/3/4), 205-214. DOI: 10.1108/02644400410519749

Zhang, Y. (2018). Mechanical Behavior of Granular Material Considering Particle Breakage, Ph.D. Dissertation, University of Lorraine, Nancy, France.

Article submitted: March 22, 2020; Peer review completed: May 24, 2020; Revised version received: August 10, 2020; Accepted: August 14, 2020; Published: August 21, 2020.

DOI: 10.15376/biores.15.4.7660-7670 